\title{
Development and Implementation of an NAE Grand Challenge Scholars Program: A Case Study at North Carolina State University
}

\author{
David Parish, PhD., Jerome Lavelle, PhD., Louis Martin-Vega, PhD. \\ North Carolina State University, USA, dwparish@ncsu.edu, lmartinv@ncsu.edu, \\ North Carolina State University, USA, jerome_lavelle@ncsu.edu
}

\begin{abstract}
The vision of the Grand Challenge Scholars Program (GCSP) in the College of Engineering (COE) at North Carolina State University is to maintain and enhance our College's global reputation for excellence and to be a world-class leader and international model for facilitating intellectual property and technology transfer. The program addresses the fourteen Grand Challenges established by the National Academy of Engineering, by providing diverse educational possibilities, global-scale research alternatives, and numerous entrepreneurial or service learning opportunities for our students. This paper addresses the development and implementation of this program.
\end{abstract}

\section{INTRODUCTION}

The NAE Grand Challenge Scholars Program [1] was created and endorsed by the U.S. National Academy of Engineering in 2009. The purpose was to support the education of a new generation of engineers equipped to tackle the most pressing issues facing society in the $21^{\text {st }}$ century. The program promotes student competency in five areas through curricular, co-curricular, and extra-curricular experiences. Competency areas include research/creative, multicultural, multidisciplinary, social consciousness, and business/entrepreneurship. This case study describes the development and implementation of the Grand Challenge Scholars Program (GCSP) at NC State University in 2012. This program fits the academic culture of the College [2].

\section{VISION}

The GCSP progressively expands the capabilities of its members, both personally and professionally, by broadening their outlook on societal concerns and promoting social responsibility and lifelong involvement in the problems facing the world in the $21^{\text {st }}$ century. The College is actively engaged in the five curricular components represented by the program. GSCP students, in cooperation with faculty mentors, industry, and government, have begun to lead the expansion of the tenets of the Grand Challenges through discoveries, recognized scholarly publications, and information exchange. The formal implementation of the program has assisted us in

Digital Object Identifier (DOI): http://dx.doi.org/10.18687/LACCEI2018.1.1.87 ISBN: 978-0-9993443-1-6

ISSN: 2414-6390 developing world-class capabilities for interdisciplinary research and education and attracting a diverse set of students.

\section{MISSION}

The College of Engineering's mission is to lead discovery, learning, and innovation by creating and disseminating knowledge, empowering significant advances in technology, and driving economic development, for the welfare of the state, the nation, and the world. The Grand Challenge Scholars Program exemplifies this mission by increasing the awareness of our future engineers in the challenges that face our world today. Paraphrasing our core values and guiding principles: we believe that a student empowered with a quality education has confidence, is able to take risks, finds innovative solutions to problems, and ultimately will have the ability to make the world a better place. By providing diverse educational possibilities, global-scale research alternatives, and numerous entrepreneurial or service learning opportunities, our Grand Challenge scholars are able to broaden their outlook on societal concerns and promote social responsibility and lifelong involvement in the problems facing the world in the 21st century. These Grand Challenge Scholars, in cooperation with faculty mentors, industry, and government, have begun leading the expansion of the tenets of the Grand Challenges.

\section{EARLY STUDENT ENGAGEMENT}

\section{A. Recruiting and Outreach}

Long before engineering students begin their academic career at NC State University, they are introduced to the concepts of the Grand Challenges. In middle and high school visitation programs such as Engineering Bits and Bytes, Engineering on the Road, and Engineering Summer Camps, perspective engineering students are acquainted with the concepts of the Grand Challenges. Once they enter the college, their familiarization with the program is beneficial in gaining membership in the GCSP.

\section{B. Freshman Orientation}

Once new engineering students enter NC State, faculty and administrators describe the intersection of societal problems with solutions from engineering disciplines to promote early 
student engagement. With the interdisciplinary nature of engineering and the challenges facing today's society, all incoming freshman are introduced to the principles of the Grand Challenges at the New Student Orientation prior to the beginning of classes in the fall.

\section{Coursework}

The GCSP is marketed to all freshman engineering majors through the two required first year engineering courses. The first course, E101-Introduction to Engineering and Problem Solving utilizes handbooks and lectures to describe the grand challenges, with the context of the GCSP program integrated into class discussions. Additional recruiting and marketing materials are distributed in class. The emphasis of the course is centered on multidisciplinary teams required to research, advance, and present design projects. Students may incorporate any of the principles of the program in the required group presentation at the end of the semester.

In the second course, E102-Engineering in the $21^{\text {st }}$ Century, the emphasis is on the fourteen NAE Grand Challenges of engineering. Students are encouraged to show the relationships of design and technical principles of individual engineering disciplines to multiple engineering grand challenges. The instructors help identify high impact activities related to the challenges and their intersection with specific engineering disciplines taught in the College. The curriculum engages students with an interactive learning experience on the challenges while incorporating video guest lectures on engineering fields of study.

\section{GC PROGRAM COMPONENTS}

The importance of a student's experience in the program is based upon the completion of the five Grand Challenge curricular components. Scholars are required to undertake activities in each of the following components: Research, Interdisciplinary Curriculum, Entrepreneurship, Global Awareness, and Service Learning. In addition, GCSP students are expected to gain both breadth and depth in the GC program. For depth, scholars are expected to complete multiple assignments in three of the listed curricular components, with Research and Interdisciplinary Curriculum being mandatory for all students. For this third depth component, students choosing to complete more than one undertaking in any of the three remaining components (Entrepreneurship, Global Awareness, or Service Learning), complete the obligation. To add breadth to their program, all remaining components are addressed by completing at least one task accentuating their focus area. The curricular components and their individual requirements are shown in figure 1.

\section{A. Research}

Each GC Scholar must prepare to help solve the engineering grand challenges that this nation and world face.
Each GC Scholar must complete a GC Capstone experience and take advantage of one or more of the following:

1) Engage in a minimum of one semester of undergraduate research in an approved team or individual research or design project with a university faculty member, focusing the research on one of the grand challenge themes. The students are required to present their findings in a poster exhibition at one of the university's undergraduate research symposiums.

2) Complete an Entrepreneurial Initiative project approved by the instructor, the student, and the student's GC Mentor focusing on a grand challenge theme. The students are also required to present their findings in a poster exhibition.

3) Complete an appropriately approved Independent Study project focusing on a grand challenge theme. Presenting their findings at one of the university's undergraduate research symposiums is also required.

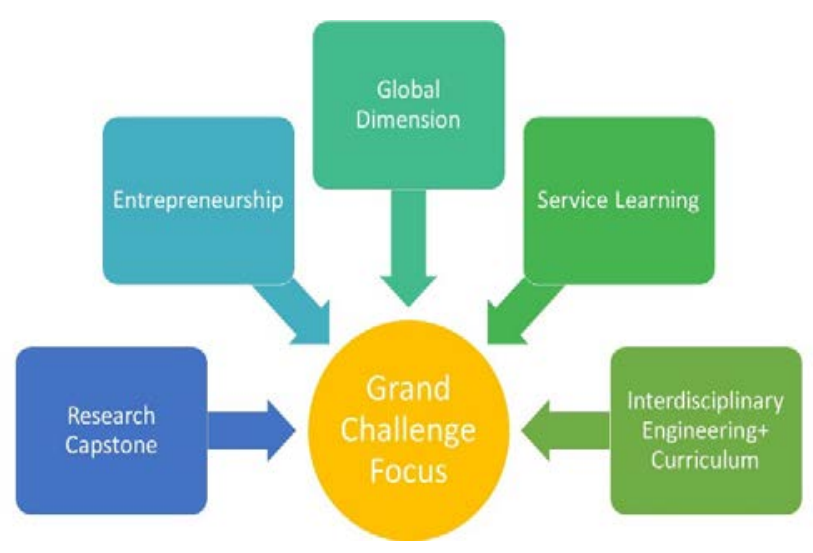

Figure 1. The five components of the Grand Challenge Scholars Program

\section{B. Interdisciplinary Curriculum}

Each GC Scholar must prepare to work at the overlap of public policy, business, law, ethics, human behavior, medicine, and risk as well as other sciences. Each GC Scholar must take advantage of one or more of the following: complete a minor in an approved interdisciplinary program, perform an internship with an interdisciplinary focus, complete a research experience with an interdisciplinary focus or take course(s) relating to a Grand Challenge theme.

\section{Entrepreneurship}

A GC Scholar is capable of translating invention and innovation into market ventures and possibly global solutions required for the public's interest. To complete the focus area, students take advantage of approved entrepreneurial experiences or internship with a significant entrepreneurial

16 $^{\text {th }}$ LACCEI International Multi-Conference for Engineering, Education, and Technology: "Innovation in Education and Inclusion", 19-21 July 2018, Lima, Peru. 
focus. Research experiences with an entrepreneurial focus or course(s) which focus on entrepreneurship also complete the obligation.

\section{Global Awareness}

A perspective necessary to address challenges that are inherently global as well as to lead innovation in a global economy is another of the tenants of the program. Each scholar undertakes and approved international experiences or internship or co-op with a significant global focus. Emphasis is placed the NC State Study Abroad Program which offers a myriad of options to study abroad. Finally, courses the detail global experiences can be taken as a substitute for a travel abroad.

\section{E. Service Learning}

To develop and deepen their social awareness and demonstrate motivation to bring technical expertise to bear on societal problems, each scholar takes advantage of approved service learning programs or volunteers with a servicelearning organization. Students can also become associated with the Center for Student Leadership, Ethics, and Public Service, an organization that focuses on service learning.

\section{STUDENT SELECTION}

Students interested in the Grand Challenge Scholar Program must have quality grades to apply as academic achievement is an important predictor of success in the program. However, the student's response on the proposed GC Portfolio and evidence of a sustained early commitment to the program are the major factors considered in a prospective applicant. The Portfolio addresses the student's GC Focus Area, Research Component (a plan or prospectus), a budget plan for component expenses, summits, etc., and any other letters of support the student wished to include. Successful candidates are notified of their acceptance by the Program Director.

\section{GC MENTOR}

Each applicant selects a GC Mentor (i.e., engineering faculty member) who guides them through the entire GC Scholars program. The mentor reviews the student's initial portfolio and submits a letter of commitment along with the student's application to the Oversight Committee. Scholars are required to meet with their mentors every semester to provide progress updates on their present program and to plan for the next semester's goals. Upon conclusion of the program, the GC Mentor writes a letter of completion to the GC Oversight Committee in support of the GC Scholar's application to be named an NC State College of Engineering Grand Challenge Scholar.

\section{PROGRAM SEQUENCE:}

The Grand Challenge Scholars Program at NC State allows students to choose the path most desirable to their academic needs. There is no specific sequence for completing the program; however, a typical model for successfully carrying out all the requirements is shown in figure 2 .

To complete the program, students are expected to present their research project at a summit, research symposium or at the National GC Summit preferably during their senior year of school.

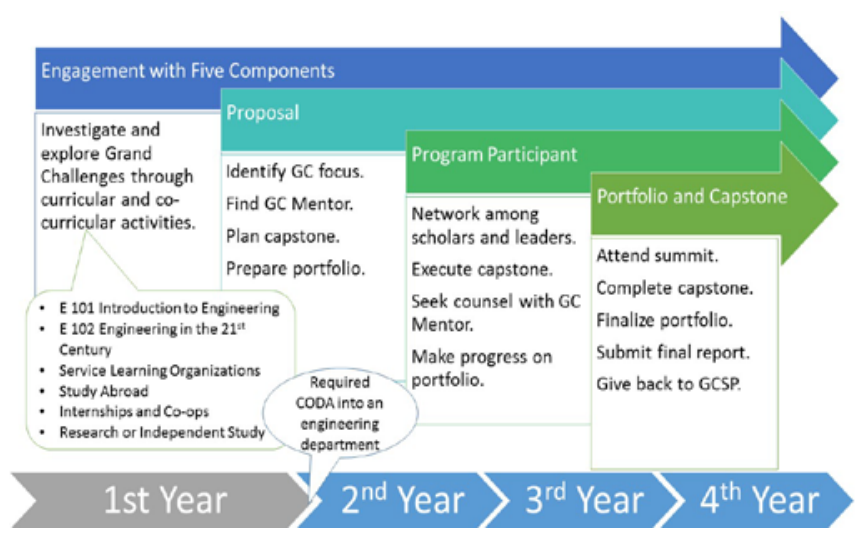

Figure 2. Program sequence

Additionally, a final report defining the completion of each of the five curricular requirements of their plan and the overall focus of their work, describing the breadth and depth of their specific program, the research component, and the student's experiences while in the program is also required. GC Scholars present their work in NC State GC-related activity to network with other scholars and to provide information to interested underclassmen. The final GC Portfolio or completion checklist is completed by the close of the semester in which the student graduates.

\section{ADMINISTRATION AND ASSESSMENT}

Maintaining the high standards expected from a quality program, assessment and success of our Grand Challenge Scholar Program is the responsibility of everyone involved. To lead this charge, the Assistant Dean for Academic Affairs in the College of Engineering serves as the Director of the GCSP. The Director is required to participate in the electronic community for the exchange of GCSP best 3practices, attends

$16^{\text {th }}$ LACCEI International Multi-Conference for Engineering, Education, and Technology: "Innovation in Education and Inclusion", 19-21 July 2018, Lima, Peru. 
workshops and summits, and prepares an annual report of programmatic accomplishments for the GCSP.

The administration and supervision of the program is performed by an Oversight Committee comprised of faculty members selected from within the College of Engineering. From the list of distinguished faculty, a Chair of the GC Oversight Committee was selected. The Program Director, along with the Oversight Chair, selected the members of the Oversight Committee. The GC Oversight Committee has the responsibility to select students and monitor their progress, approve portfolios, compile the names and accomplishments of GC Scholars, and convey all information to the Oversight Committee Chair and GC Director as part of the required annual report.

\section{PROGRAM BENEFITS}

Scholars produce their own comprehensive portfolio of research, projects and high-impact experiences that can be leveraged to pursue future academic and professional endeavors. Once accepted to the program, scholars receive a yearly academic achievement award with an annual increase to offset the expenses associated with completing the program's five programmatic components. Expenses include, but are not limited to, travel costs to present at research symposiums or study abroad. Scholars have opportunities to network with other GC Scholars at the university as well as associate with other programs across the world. Graduating seniors will be distinctly recognized as Grand Challenge Scholars on their official university transcript and acknowledged by the NAE upon completion of the program.

\section{NC STATE GCSP SCHOLARS}

Table 1 below provides details of recent graduates and current scholars from the College's GCSP. Students in the program come from all programmatic areas in the college, and each scholar can design their GCSP experience in a manner consistent with their interests and goals. This is evident by the sample of experiences given in the table.

\begin{tabular}{|c|c|l|}
\hline Major & NAE GC & GCSP Research Theme \\
\hline $\mathrm{AE}$ & 2 & Tools of Scientific Discovery \\
\hline $\mathrm{BME}$ & 3 & Reverse Engineer the Brain \\
\hline $\mathrm{CE}$ & 2 & Restore Urban Infrastructure \\
\hline $\mathrm{CSC}$ & 3 & Virtual Reality \\
\hline $\mathrm{ME}$ & 2 & Make Solar Energy Economical \\
\hline $\mathrm{CHE}$ & 1 & Access to Clean Water \\
\hline
\end{tabular}

Table 1: Sample of Current NC State GCSP students

\section{FINAL THOUGHT}

The conversion of "ideas into reality" to solve pressing societal needs has always been a major focus of Engineering. The Grand Challenge Scholars Program aids students in exploring grand challenges along with their educational and research directions in ways that best serve the needs and future of our state, region, and local constituencies. They strive to be globally competitive and are much more aware of crosscutting interdisciplinary efforts. Finally, it is our responsibility as engineering educators to assure that our students graduate with both the breadth and depth needed to be major players in addressing and solving the societal grand challenges facing our nations and the world. We are convinced that the Grand Challenge Scholars Program is playing a critical role in our College in helping us achieve this result.

\section{REFERENCES}

[1] National Academic of Engineering, Grand Challenge Scholars Program website at:

http://www.engineeringchallenges.org/GrandChallengeScholarsProgram.aspx, accessed January 29, 2018.

[2] J. Lavelle and L. Bottomley, "NAE Grand Challenges and Academic Culture in Engineering Education,” Proceedings of 2011 ASEE Southeast Regional Conference, Charleston, SC, April, 2010.

$16^{\text {th }}$ LACCEI International Multi-Conference for Engineering, Education, and Technology: "Innovation in Education and Inclusion", 19-21 July 2018, Lima, Peru. 